\title{
UAV IMAGE FAST GEOCODING METHOD FOR DISASTER SCENE MONITORING
}

\author{
H. Nho ${ }^{1}$, D.Y. Shin ${ }^{1}$, S.S. Kim ${ }^{1, *}$ \\ ${ }^{1}$ National Disaster Management Research Institute, Disaster Scientific Investigation Division, 365, Jongga-ro, Jung-gu, Ulsan, \\ Korea, 44538, (nhj1017, sdy718, sskim73)@korea.kr
}

\section{Commission IV}

KEY WORDS: UAV, Fast geocoding, Spatial information, Disaster

\begin{abstract}
:
Recently, UAVs are being used in various fields such as photography, precision agriculture, remote monitoring, surveying, mapping, and disaster management. In particular, UAVs can acquire real-time data and access hard-to-reach areas, which is advantageous for rapid spatial information generation. Spatial information can be generated by mounting a camera on the UAV and performing the geocoding process of image data using the location/location information acquired from the GPS/INS sensor. The use of multiple GCPs during the geocoding process can increase the image position accuracy. However, since a lot of time is consumed for surveying, it is disadvantageous to be used in disaster fields that require urgent data generation. Therefore, in this study, fast geocoding process of UAV image using the minimum GCP is proposed. The results obtained through this process can be used as basic data for on-site monitoring and decision-making in disasters and emergencies.
\end{abstract}

\section{INTRODUCTION}

\subsection{Introduction}

Recently, the use of spatial information is increasing in the private sector as well as in the public sector such as land use and management, and map services. In particular, it is possible to present important basic information and standards by using spatial information when determining the behavior in everyday life or in a specific situation.

Spatial information data can be acquired through various platforms such as LiDAR, satellite, and UAV. Recently, interest in the use of UAVs, which are relatively efficient in terms of time, cost, and manpower required for operation, has increased compared to others.

By geocoding the data obtained from the UAV, it can be used in various fields such as road facility survey, cultural property survey, map production, disaster monitoring. Among these various fields of use, this study proposes rapid UAV image geocoding method by correcting external elements to generate basic data necessary for the decision making process in the disaster/accident field.

\subsection{Bundle Adjustment}

Bundle Adjustment is a method of determining the most probable value of the EOP(Exterior orientation parameters) and unknown ground coordinates using the ground control point and the photo coordinates of the point observed on each photo.

Bundle adjustment is classified as space resection and space intersection. Space resection is used when the location on the map is unknown, and the location is determined using 2 or 3 unknown points. Space intersection is a process of obtaining a $3 \mathrm{D}$ coordinate using six expression factors and $\mathrm{x}$, $\mathrm{y}$ determined by space resection.

Mathematical model of bundle adjustment can be expressed as a collinearity condition as shown in the figure below.

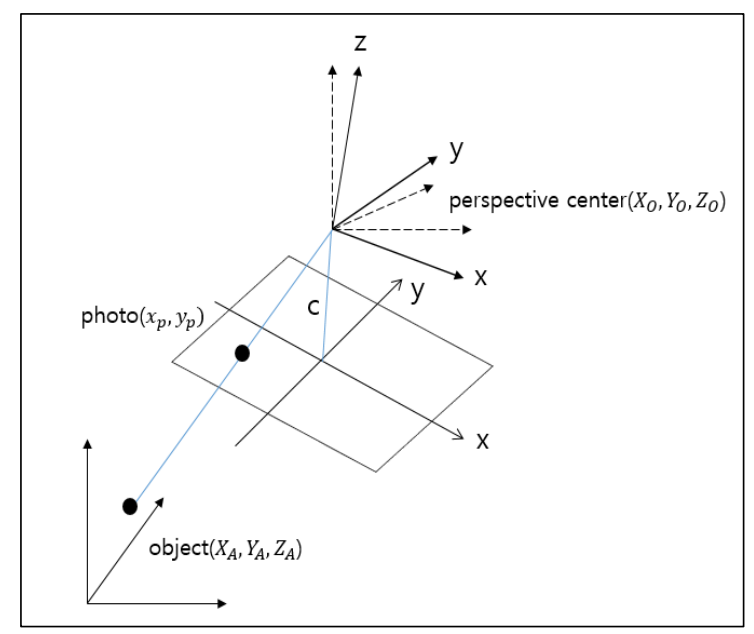

Figure 1 Collinearity Condition

The collinearity condition equation for the ground point $\mathrm{j}$ of the image I is equal to follow equations.

$$
\begin{gathered}
F_{X}=\left(\omega_{i}, \varphi_{i}, \kappa_{i}, X_{0 i}, Y_{0 i}, Z_{0 i}, X_{j}, Y_{j}, Z_{j}\right) \\
x_{i j}=x_{p}-c \frac{r_{11}\left(X_{A}-X_{O}\right)+r_{12}\left(Y_{A}-Y_{O}\right)+r_{13}\left(Z_{A}-Z_{O}\right)}{r_{31}\left(X_{A}-X_{O}\right)+r_{32}\left(Y_{A}-Y_{O}\right)+r_{33}\left(Z_{A}-Z_{O}\right)} \\
F_{y}=\left(\omega_{i}, \varphi_{i}, \kappa_{i}, X_{0 i}, Y_{0 i}, Z_{0 i}, X_{j}, Y_{j}, Z_{j}\right) \\
y_{i j}=y_{p}-c \frac{r_{21}\left(X_{A}-X_{O}\right)+r_{22}\left(Y_{A}-Y_{O}\right)+r_{23}\left(Z_{A}-Z_{O}\right)}{r_{31}\left(X_{A}-X_{O}\right)+r_{32}\left(Y_{A}-Y_{O}\right)+r_{33}\left(Z_{A}-Z_{O}\right)}
\end{gathered}
$$

where $\quad c:$ Focal length

$\left(\mathrm{x}_{\mathrm{a}}, \mathrm{y}_{\mathrm{a}}\right)$ : Image coordinates

$\left(\mathrm{X}_{\mathrm{A}}, \mathrm{Y}_{\mathrm{A}}, \mathrm{Z}_{\mathrm{A}}\right)$ : Ground points coordinates

$\left(\mathrm{x}_{\mathrm{p}}, \mathrm{y}_{\mathrm{p}}, \mathrm{Z}_{\mathrm{p}}\right)$ : Principal point

(Xo, $\left.\mathrm{Yo}_{\mathrm{O}} \mathrm{Zo}\right)$ : Projection center coordinates

$r_{11}, r_{12}, \ldots, r_{33}$ : Rotation matrix component 


\section{DATASET}

\subsection{Equipment}

The UAV used in this study is DJI's Inspire 1 pro as shown in Figure 2, and the specifications are shown in Table 1. The DJI Inspire 1 pro is a small-sized rotary wing UAV that enables automatic flight routing using apps such as smartphones. The camera used in the experiment is a Zenmuse X5 from DJI, which can be mounted on the DJI Inspire 1 pro, and can shoot $4,608 x$ 3,456 pixel images. Table 2 shows detailed camera specifications.

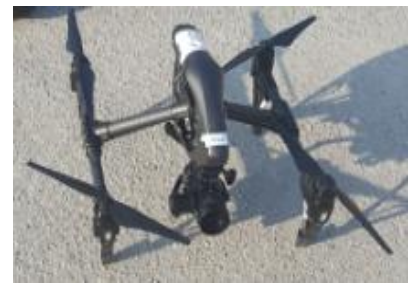

Figure 2 DJI Inspire 1 Pro

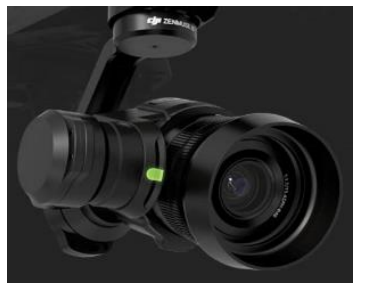

Figure 3 Zenmuse X5

\begin{tabular}{|c|c|}
\hline Item & Contents \\
\hline Max speed & $18 \mathrm{~m} / \mathrm{s}$ (ATTI mode $)$ \\
\hline Max Flight Time & Approx. 15 minutes \\
\hline $\begin{array}{c}\text { Max Service Ceiling } \\
\text { Above Sea Level }\end{array}$ & $4500 \mathrm{~m}(120 \mathrm{~m}$ above take off point) \\
\hline Max Tilt Angle & $35^{\circ}$ \\
\hline Hovering Accuracy & $\begin{array}{c}\text { Vertical:0.5m } \\
\text { Horizontal: } 2.5 \mathrm{~m}\end{array}$ \\
\hline Weight & $2870 \mathrm{~g}$ \\
\hline
\end{tabular}

Table 1 Specification of DJI Inspire 1 Pro

\begin{tabular}{|c|c|}
\hline Item & Contents \\
\hline Focal length & $15 \mathrm{~mm}$ \\
\hline Lens & F1.7-F16(default DJI lens) \\
\hline Photo Resolutions & $4608 \times 3456$ \\
\hline FOV & $72^{\circ}$ \\
\hline Weight & 530 \\
\hline
\end{tabular}

Table 2 Specification of Zenmuse X5

\subsection{UAV Image}

The research site was selected as a National disaster safety research center located in Ulsan(Figure). The metadata of each image includes basic information such as the size, date, aperture, ISO, as well as focal length, latitude and longitude coordinates of the GPS, installed in the UAV, flight altitude, and posture angle.

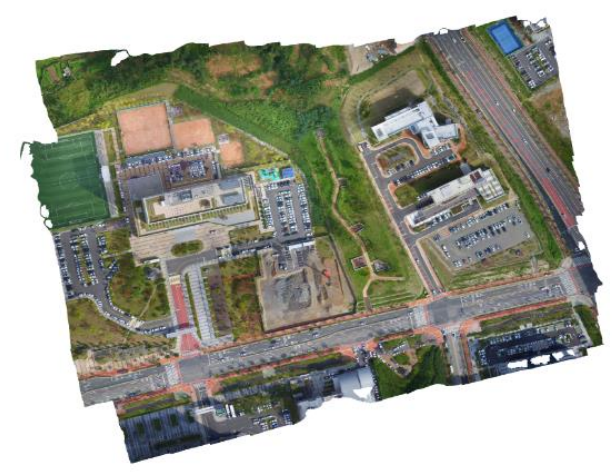

Figure 4 Research Site

\subsection{Ground Control Point}

Ground control points survey were conducted to evaluate the accuracy of the study results. As shown in Fig_, the targets were placed in the study area. GCP surveying was performed in RTK mode with high accuracy and very high processing speed, and coordinates with an accuracy of about 1 to $2 \mathrm{~cm}$ were obtained.

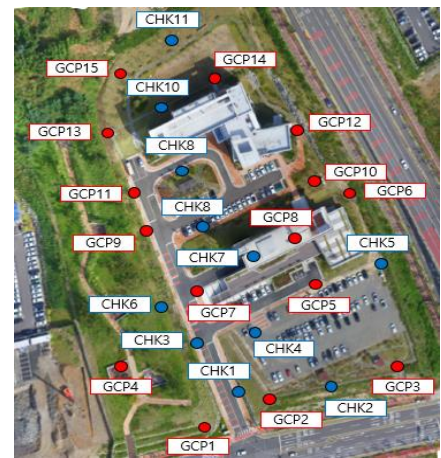

Figure 5 Location of GPS survey

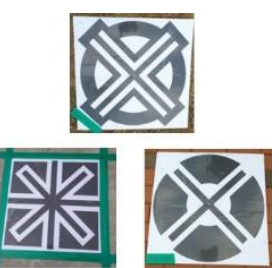

Figure 6 Used Target

\section{FAST GEOCODING}

\subsection{GPS/INS}

The GPS/INS sensor information provided by UAV itself was first analysed. Figure 7 shows the trajectory shoot with the UAV's $x$ and $y$ values. Figure 8 shows the amount of rotation in the $\mathrm{x}$ and $\mathrm{y}$ directions(roll and pitch). Figure 9 shows the height and the amount of rotation in the $\mathrm{z}$ direction(yaw).

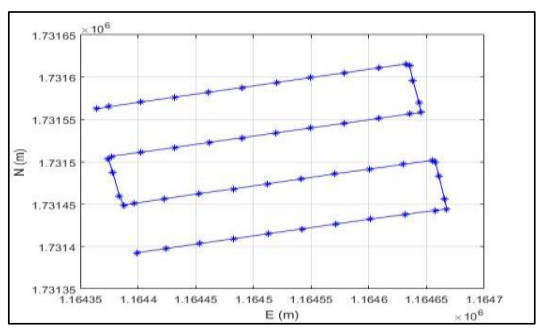

Figure 7 Trajectory

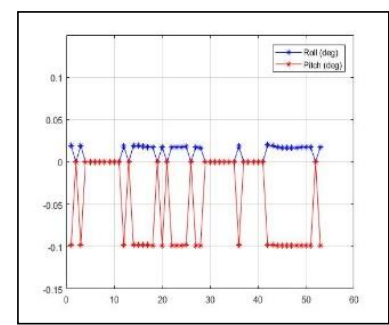

Figure 8 Roll and Pitch

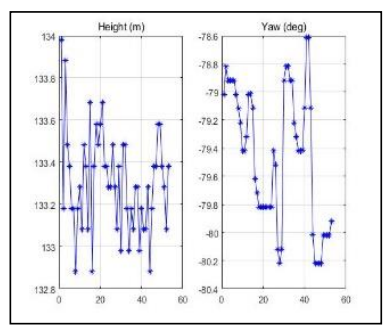

Figure 9 Height and Yaw

\subsection{Influence of Corrected Parameters}

The results of the correction for the initial EOP are as follows. It was confirmed that $\mathrm{X}$ and $\mathrm{Y}$ shows a random error, while $\mathrm{Z}$ and kappa shows a systematic error. 


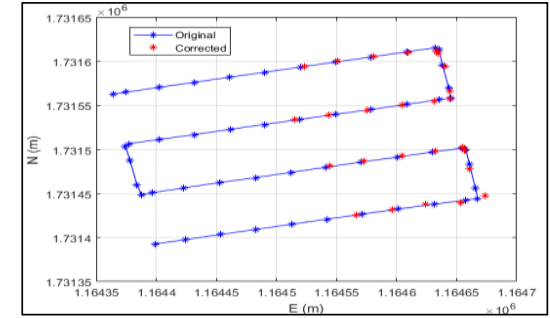

Figure 10 Trajectory

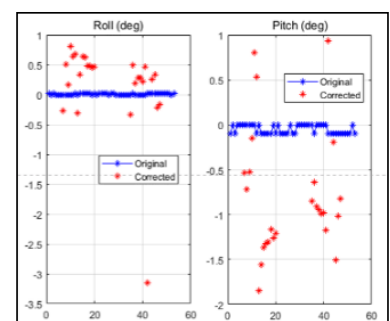

Figure 11 Roll and Pitch

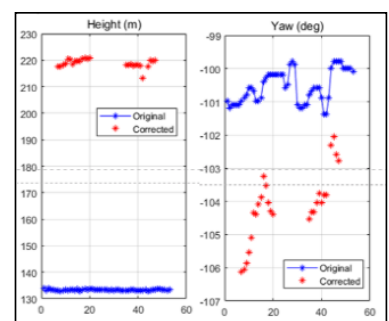

Figure 12 Height and Yaw
Based on the above result, the correction parameters were divided to each case, and check the position accuracy. The following table shows the parameters to be corrected for each case.

\begin{tabular}{|c|c|c|}
\hline Case & Correction Factor & $\begin{array}{c}\text { Theoretical required } \\
\text { number of GCPs }\end{array}$ \\
\hline Case 1 & EOP, f, xp, yp, k1,k2 & 6 \\
Case 2 & EOP, f, xp, yp & 5 \\
Case 3 & EOP, $\mathrm{f}$ & 4 \\
Case 4 & $\mathrm{EOP}$ & 3 \\
Case 5 & $\mathrm{X}, \mathrm{Y}, \mathrm{Z}$ & 2 \\
Case 6 & $\mathrm{X}, \mathrm{Y}, \mathrm{Z}, \kappa$ & 2 \\
Case 7 & $\omega, \varphi, \kappa$ & 2 \\
Case 8 & $\mathrm{X}, \mathrm{Y}, \kappa$ & 2 \\
Case 9 & $\mathrm{X}, \mathrm{Y}$ & 1 \\
Case 10 & $\mathrm{Z}, \kappa$ & 1 \\
\hline
\end{tabular}

Table 3 Theoretical required number of GCPs per correction factor

The maximum number of GCPs required in theory is 6. In this part, the experimental image was selected as CAM 17 with 12 GCPs in the image, and assume that there are 8 GCPs in each case.

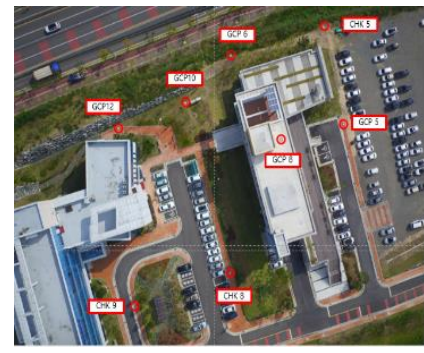

Figure 13 CAM 17

\begin{tabular}{|c|c|}
\hline Case & Pixel Error(pixel) \\
\hline Case 1 & $\mathrm{rms}=[3.55 / 6.01]$ \\
\hline Case 2 & $\mathrm{rms}=[2.17 / 4.82]$ \\
\hline Case 3 & $\mathrm{rms}=[1.54 / 1.88]$ \\
\hline Case 4 & $\mathrm{rms}=[1.73 / 1.97]$ \\
\hline
\end{tabular}

\begin{tabular}{|l|l|}
\hline Case 5 & $\mathrm{rms}=[62.93 / 55.10]$ \\
\hline Case 6 & $\mathrm{rms}=[7.75 / 7.65]$ \\
\hline Case 7 & $\mathrm{rms}=[2555.29 / 2602.36]$ \\
\hline Case 8 & $\mathrm{rms}=[10870.17 / 6225.38]$ \\
\hline Case 9 & $\mathrm{rms}=[2624.84 / 2818.07]$ \\
\hline Case 10 & $\mathrm{rms}=[102.32 / 102.24]$ \\
\hline
\end{tabular}

Table 4 Error for each case

In this process, it is confirmed that the case 4 , case 6 , and case 10 indicate $5 \mathrm{~cm}, 23 \mathrm{~cm}, 3 \mathrm{~m}$ errors, respectively.

\subsection{Influence of Number of GCPs}

In disaster and emergency situations, it is difficult to survey a large number of GCPs. Therefore, the position accuracy of the image is confirmed when using a limited number of GCPs. Based on the results from the previous part, Case 4, 6, and 10 where 3 , 2 , and $1 \mathrm{GCP}$ were required were used for analysis.

In order to shorten the time, instead of correcting all the images, a method of applying the correction values for one image to all the remaining images was performed.

The equation below shows the process of obtaining the correction values, and the table shows the correction values for Case 4 .

\begin{tabular}{|c|c|}
\hline Parameter & Correction value \\
\hline$\Delta \mathrm{X}$ & $6.6282 \mathrm{~m}$ \\
\hline$\Delta \mathrm{Y}$ & $-0.7649 \mathrm{~m}$ \\
\hline$\Delta \mathrm{Z}$ & $84.3671 \mathrm{~m}$ \\
\hline$\Delta \varphi$ & $0.3827 \mathrm{deg}$ \\
\hline$\Delta \varphi$ & $-1.5689 \mathrm{deg}$ \\
\hline$\Delta \mathrm{K}$ & $-5.1871 \mathrm{deg}$ \\
\hline
\end{tabular}

Table 5 Correction value of each parameter

The results of each case through the above process are shown in the table below.

\begin{tabular}{|c|c|c|}
\hline Case & Number of GCPs & RMSE \\
\hline Case 4 & 3 & $2.0 \mathrm{~m}$ \\
\hline Case 6 & 2 & $1.9 \mathrm{~m}$ \\
\hline Case 10 & 1 & $7.4 \mathrm{~m}$ \\
\hline
\end{tabular}

Table 6 RMSE for each case

\subsection{Generate Geocoding Image}

At the last step, a geocoding image was created based on the above result. Bilinear interpolation was used as the image rearrangement method.

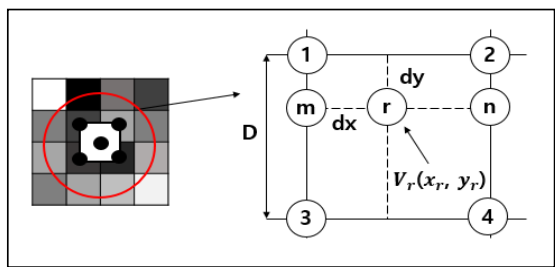

Figure 14 Bilinear interpolation 


\section{CONCLUSION}

In this study, the fast geocoding process using a minimum GCPs was proposed in emergency situations such as disaster and accident sites. This process can reduce the time spent on GCPs surveying in the field, and it was confirmed that the generated image has adequate accuracy for field monitoring.

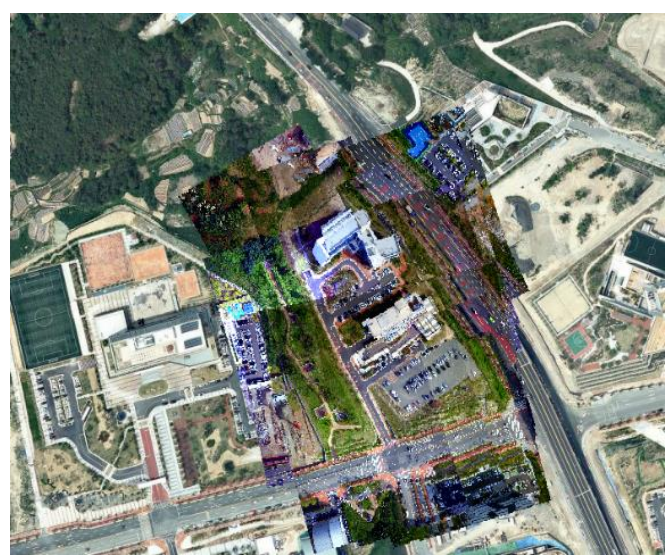

Figure 15 Usability review

The created image was reviewed for usability through open software QGIS. Therefore, it is considered that the result generated by the fast geocoding process can be sufficiently utilized as basic data for decision-making of initial response measures or recovery work in emergency situations. For the future study, geocoding image generating for rapid monitoring without GCP will be conducted.

\section{ACKNOWLEDGEMENTS}

This research outputs are part of the project "Development of forensic techniques for Disaster Scientific Investigation", which is supported by the NDMI (National Disaster Management Research Institute) under the project number NDMI-MA-201905-01. The authors would like to thank the financial support of the NDMI.

\section{REFERENCES}

Han, S.H., Jung, K.Y., 2015. Accuracy Evaluation of UAV based on GCP Usage. Korean Society of Surveying, Geodesy, Photogrammetry, and Cartography 2015.4, 555-256

Lee, J.O., Sung, S.M., Yun, B.Y., Accuracy Analysis of UAV Photogrammetry Based on the Number and Distribution of Ground Control Points. Korean Society of Surveying, Geodesy, Photogrammetry, and Cartography 2016.4, 133-135

Lim, J.H., Seo, C.W., Lee, J.S., Yun, H.C., 2015. Ortho-image Production Utilization Evaluation using UAV System. Korean Society of civil engineers 2015.10, 13-14

Choi, K.A., Lee, I.P., 2013. Fast Sequential Bundle Adjustment Algorithm for Real-time High-Precision Image Georeferencing. Korean Journal of Remote Sensing, 29(2), 183-195 